www.nature.com/clinicalpractice/rheum

\title{
A tyrosine kinase inhibitor successfully treats RA in rats
}

Nature Clinical Practice Rheumatology (2008) 4: 11 [doi:10.1038/ncprheum0669]

\section{ERRATUM}

In a Research Highlight in the January 2008 issue, collagen-induced arthritis was incorrectly referred to as rheumatoid arthritis in the title, line 13 and 14 of the second paragraph, and in the concluding paragraph. doi:10.1038/ncprheum0986 